\title{
Similarities and Differences between Adult and Child Learners as Participants in the Natural Learning Process
}

\author{
Darlene McDonough \\ School of Education, St. Bonaventure University, New York, USA \\ Email:dmcdonou@sbu.edu, mcdonoughdar@aol.com
}

Received December 27 $7^{\text {th }}$, 2012; revised January $28^{\text {th }}$, 2013; accepted February $27^{\text {th }}, 2013$

\begin{abstract}
This paper compares Brian Cambourne’s Conditions of Learning (1988), APA's Learner-Centered Psychological Principles (1997), and Malcolm Knowles’ Adult Learning Theory (2011). These theories embrace the natural learning process and not the traditional view of learning. The traditional view suggests that the teacher has the knowledge, the learner is dependent on the teacher to disseminate the knowledge and the learner has nothing to contribute. In the natural learning process, knowledge is distributed in a circular and reciprocal way through a collaborative sharing of experiences, centered on real life situations, and learners are responsible for their own learning. In the 21st century knowledge is constantly changing and expanding exponentially. The natural learning process facilitates the life-long learning that is needed to remain a valuable contributor in society where learning has become a collaborative experience.
\end{abstract}

Keywords: Similarities in Adult and Child Learning; Adult Learning; Child Learning

\section{Introduction}

The concept of life-long learning has taken on a new meaning as the world of knowledge and technology changes at an exponential rate. Adults have a choice to either keep up with the changes by improving their knowledge and skills or stagnate in their learning and become obsolete (Billington, 2006). This has created the need for a deeper understanding of how adults learn, how this learning can be facilitated, and how this process compares to what is known about how children learn. This paper summarizes the connections between the research of Brian Cambourne's Conditions of Learning (1988), APA's Learner-Centered Psychological Principles (1997), and Knowles' Adult Learning Theory (2011). The similarities and differences between adult and child learners as participants in the natural learning process are discussed.

\section{Conditions of Learning}

Brian Cambourne (1988) developed a model of learning based on how children acquire speech. It was based on observing what children do as they learn to talk. There are Seven Conditions of Learning in Cambourne's model: 1) immersionthe learner is surrounded in what is being learned in an authentic, real life situation; 2) demonstration-the learner experiences (sees, hears, views, witnesses, feels, explores, studies) actions and artifacts that model what is to be learned; 3) engagement-learning will only take place when the learner actively participates in the demonstrations which are constantly occurring around them; 4) expectations-powerful and subtle messages that significant others communicate to the learners that they have the capacity to be successful learners and they are expected to learn; 5) responsibility-learners are allowed to make decisions about what will be engaged in and what will be ignored during the immersion of demonstrations presented in meaningful contexts with a relevant purpose; 6) approximations-learners are encouraged to attempt to use the new knowl- edge gained through immersion in demonstrations as a way to receive feedback and move toward the conventional learning; 7) employment-opportunities and time for learners to use the knowledge gained through immersion in demonstrations in social contexts with other language users and alone in real life situations to gain command of the conventions of the learning; and 8) response-feedback that learners receive when employing the developing language through interactions with other language users. These conditions need to be implemented for any learning endeavor to be successful and not just the learning of language.

\section{Learner-Centered Psychological Principles}

The American Psychological Association Task Force on Psychology of Education along with the Mid-Continent Regional Educational Laboratory developed 12 Learner-Centered Psychological Principles (1993). In 1997, the American Psychological Association Work Group of the Board of Educational Affairs revised the 1993 principles to the Learner-Centered Psychological Principles: Two additional factors were added to the category of Individual Differences Factors: 1) diversity; differences in linguistics, culture, social background and 2) standards and assessment; high standards, diagnostic, process and outcome assessments of learner and process. The principles were divided into four categories: 1) Cognitive and Metacognitive Factors; 2) Motivational and Affective Factors; 3) Developmental and Social Factors; and 4) Individual Differences Factors. The Learner-Centered Principles focus on the active and reflective characteristics of all learners and all learning situations. These are psychological characteristics and under the control of the learner. However, the principles also take into consideration contextual and environmental factors that impact the learner and the learning process. No factor is intended to be taken individually, but holistically in the context of real world situations. 


\section{Cognitive and Metacognitive Factors}

Principle 1, natural of the learning process, is defined as an intentional construction of meaning from experience and information of the learner's thoughts and beliefs. Successful learners are actively engaged in the learning process by being self-directed and personally responsible for their learning. Due to the strategic nature of the learning process, successful learning needs the learner to set personally relevant goals, according to principle 2 . The result is meaningfully, coherent representations of knowledge. Principle 3 states successfully learners connect new learning in a variety of ways such as rearranging, altering, adjusting, or adapting to prior knowledge. This connection insures the transferability of the internalized new learning to new situations. Strategic thinking, principle 4, states that successful learners use a variety of reasoning and thinking strategies to attain intricate learning goals. Through application of problem solving and reasoning strategies, successful learners reflect on which strategies work best is certain kinds of situations to continue to expand their strategic thinking capacity. Principle 5 focuses on thinking about thinking. Learners develop creative and critical thinking skills through the use of higher order metacognitive strategies that focuson self-reflection regarding the attainment of learning goals. Learning is affected by the context in which it takes place including culture, technology, motivation, prior knowledge, metacognitive strategies, and environmental elements.

\section{Motivational and Affective Factors}

Principle 7 concentrates on motivation and emotional influences that impact successful learning. Learners' internal beliefs, goals, metacognitive strategies, and interests facilitate motivation to learn, the quality of thinking and information processing. Intrinsic motivation to learn is influenced by the creativity, natural curiosity, and metacognitive strategies of the learner, according to principle 8 . To be successful, learners make choices that increase knowledge based on interest, personal significance, and focus on real life situations where the learner exercises personal choice and control. Principle 9 states that attaining complex understandings and strategies involves effort and opportunities for practice by the learner in personally relevant tasks. The results of intrinsic motivation, perseverance, and commitment are successful learners who actively participate in the learning process.

\section{Developmental and Social Factors}

Principle 10 centers on developmental impacts on learning across physical, intellectual, emotional, and social domains. Learners are most successful when what is being learned is at the appropriate developmental level and the learner is able to connect the new knowledge to prior life experiences. At times, successful learners may be able to demonstrate the learning in one domain and not all the domains based on their cognitive, emotional, and social development as well as how home, school, culture and community experiences can be aligned to the new learning. According to principle 11, developing positive personal relationships through social interactions and collaboration where there is trust and respect for diversity, provide learners stability and support as well as allow reflective and flexible thinking. Positive social contexts help learners feel safe to share ideas, actively engage in the learning process, become part of a learning community, and take risks to gain knowledge.

\section{Individual Differences Factors}

Principle 12 explains the factors that cause individual differences in successful learners. Learners are born with individual capacities, talents, interests, ways of learning, and pace of learning. These areas continue to develop throughout the life of the learner. The learning environment and the learner's goals interact with the individual learner differences and adaptions are made as needed to make the learner successful. Differences in a learner's ability, experiences, language, ethnicity, race, beliefs, and socioeconomic status have an impact on learning and should be taken into account when developing the learning environment, according to principle 13. Learners are successful when individual differences in these factors are respected, valued, and accommodated in learning opportunities and contexts. As a result, there is an increase in motivation, engagement and knowledge gained. Principle 14 describes the role of setting high and challenging standards and assessments. These include diagnostic, process monitoring and outcome based assessments in the learning process. Learners are successful when they are challenged to meet high expectations. Ongoing assessment throughout the learning process, gives the learner important feedback about progress toward the learning goals which enhance motivation and self-directed learning. Various assessments can be used based on the learning goals including performance assessments, project-based assessments, self-appraisal, problem/solution etc.

\section{Malcolm Knowles Principles of Adult Learning}

Malcolm Knowles (2011) defined andragogy as the art and science of helping adults learn and described self-inquiry as the adult learning process. There are certain assumptions regarding how adults learn. Adult learning is viewed as problem-based and collaborative not didactic. Adults are self-directed and autonomous and determine individual learning goals. As self-directed learners, they want to determine the knowledge that will be learned, the projects in which they will participate, and how they will demonstrate the knowledge gained. Adults who are self-directed take the initiative, with or without the help of others, in determining their learning needs, obtain human and material resources for learning, choose and implement appropriate learning strategies, and assess learning outcomes. Knowles argues that self-directed learning is closely related to the natural process of psychological development-where adults take on increased responsibility for their own lives and their own learning. Self-directed learners are proactive, learn more things and learn better, than do learners who are reactive learners and are passively engaged in the learning. They enter into learning with greater motivation and more purposeful. As a result, new knowledge is retained better and longer, as well as applied with greater ease to new situations. Adult learners have a variety of life experiences and prior knowledge from work, school, family, and community involvements. Respect for adult learners needs to be demonstrated during the learning process, in particular acknowledging the wealth of knowledge and experiences they bring to the learning situation. Adult learners need to be treated as equals in the learning situation and be given opportunities to communicate freely. Connections need to 


\section{MCDONOUGH}

be made by the learner between prior knowledge and the new knowledge. These connections help the adult learner see the value of the new knowledge to real life situation and enable the learner to apply the new knowledge to meaningful situations. Adult learners are goal oriented. According to the Adult Education Center (2005), most adults engage in a learning experience to create a change in a skill, behavior, current knowledge, or attitude. Learning needs to focus on tasks involving a component of the learner's social roles. Adult learners are motivated to learning that can have immediate application to their real life situations. The adult learner needs to have a reason for the learning. Application to the learner's work or other responsibilities, help the adult learner see value in gaining the new knowledge. Adult learners are practical and focus on the parts of the new knowledge that are most useful to them; either in their work or other areas of their life.

\section{Motivation in Adult Learners}

Malcolm Knowles (2011) indicates that motivation in adult learners is both extrinsic and intrinsic. There are at least six factors that impact the motivation of adult learners. The need to make new friendships and engage with new associates may be motivation for adult learners to engage in social relationships. Meeting the external expectation or recommendation to participate in new learning from someone in authority could be a second motivating factor. Adults may become motivated to get involved in new learning for personal advancement such as achieving a job promotion, obtain advanced status in employment, or stay competitive. Obtaining or maintaining a license/ certification, maintaining/developing skills, or adapting to changes within a job can be motivation for adult learning experiences. Motivation to obtain new knowledge, for adult learners, can be to assist the community, be better prepared to participate in community work or serve mankind. Adult learners may be motivated to acquire new knowledge to escape boredom and relief from the ordinary daily routines of work or home with a contrast of other more exciting opportunities. Learning for the sake of gaining new knowledge, obtaining knowledge for its own sake and appeasing an inquisitive mind are other motivating factors for adults to learn new information. Retention is an important part of the adult learning process. It is directly impacted by the amount of practice/use during the learning.

Adult learners have barriers to their motivation to learn. They have many personal and work responsibilities that must be balanced with the demands of learning. Lack of time, financial resources, confidence, or information regarding opportunities to learn, scheduling difficulties, as well as child care and transportation issues can impact the adult learners' motivation to learn. Past educational or work experiences may be barriers to learning. This occurs if the new knowledge is in conflict with past education or life experiences. This conflict needs to be addressed before the learners can actively engage in the learning.

Dorothy Billington (2007) is in agreement with much of Malcolm Knowles' theories on adult learning. Specifically, her research indicates that adult learners need an environment where they feel safe and supported and have individual needs and uniqueness, abilities and life achievements recognized and respected. The environment should encourage intellectual freedom, experimentation, and creativity. Environments where adult learners are viewed as equals having a multitude of life experiences and prior knowledge that are valued, respected, appreciated, and listened to are important. Adult learners are self-directed and take responsibility for their own learning by designing learning experiences that meet their individual goals. Intellectually challenging the adult learner through the appropriate individual pacing to insure growth and eliminate boredom is important to the adult learning process. Adult learners who are actively engaged in the learning process where new knowledge is connected and applied to meaningful situations, learn more. Regular, systematic feedback regarding the learning helps the adult learner adjust to insure they are gaining the knowledge they want and need to meet their individual goals.

\section{Conclusion}

Based on the similarities, the three theories can be viewed as similar ways of looking at the natural process of learning. The process described by each has the same meaning using different vocabulary. The learner, be it a child or an adult comes to the learning process with life experiences and prior knowledge that is used by the learner to make connections to the new learning. One difference is the adult learner has more life experiences and prior knowledge than the child. In all three theories, the environment in which the learning takes place needs to be risk free and one in which the learner feels safe and secure and supported to engage in new learning. Since learning is a natural process, all three theories have the expectation that learning will occur. The occurrence of learning taking place is driven by the responsibility of the learner. It is the self-directed nature of the process, as described by all three theories that determines what will be learned. There appears to be a difference in the responsibility and self-directedness between the adult learner and a child. The adult appears to have an awareness of the self-directed nature of the process and makes conscious decisions regarding the learning by formulation of learning goals. The child appears to unconsciously determine what is next in the natural process of learning based on the current skill, strategy, or knowledge that is need in the next step of the process. This is also determined by what is being learned-language, reading, writing, walking, running, etc.

The three theories indicate that for learning to take place, both adults and children need to be immersed in what is being learned. This is needed to help insure that the new knowledge is internalized to the point where the knowledge can be transferred into appropriate situations. Since adults have more prior knowledge and more life experiences to bring to the learning situation, internalization and transfer may take less time than the new learning of a child. Demonstrations or models of what is being learned are evident in the three theories. Being immersed in the demonstrations or models of what is being learned is crucial in the nature process of learning. It is the adult learner who consciously self-directs what demonstrations or models in which he/she will participate to gain new knowledge. A child is consciously immersed in demonstrations or models by the significant others in the child's life. As a result, the learning that takes place by the child is subconscious and based on where the child is in the nature learning process. An example of this is when a child requests the same book be read night after night. With each reading, the child is expanding his/her knowledge of language, reading, writing, etc. During one reading, the child may be learning the meanings of some 


\section{MCDONOUGH}

words, during the second reading the learner may be learning something about sentence structure, and during the third reading the new knowledge may be developing an understanding story structure.

Approximations in learning take place in the learning of adults as well as children. Due the natural learning process, both adults and children need to use the learning or employ the knowledge gained. The more the knowledge is used, the closer the approximations come to the conventions and become internalized. Feedback to both the adult and the child helps each learner fine tune the approximations. Once the learning has been internalized, the knowledge is transferred into new situations by both the adult and child learners. A major characteristic that impacts the natural learning process is engagement of both adult and child learners. The more actively engaged in the learning process, the faster the knowledge is obtained and the better the knowledge is learned. Both the adult and child learner need to be motivated to learn. The motivation can be intrinsic or extrinsic. Active engagement is influence by a risk free environment, self- directed learner characteristics, alignment with life experiences and prior knowledge, immersion, demonstrations, feedback, and learner responsibility as well as motivation for the adult and child learner.

In summary, both adults and children move through the natural process of learning in the same ways. Adult and child learners need: 1) a risk free environment for safety and support for the new learning; 2) to be immersed in the new learning; 3) models/demonstrations of the new learning; 4) intrinsic and extrinsic motivation; 5) to actively engage in the learning process; 6) opportunities to employ/use the new learning; 7) to be given the responsibility for their own learning; 8) to use approximations until the new learning becomes internalized and transferable; 9) feedback to help the learning become internalized and help move approximations to conventions, and 10) to connect the new learning to prior knowledge and life experiences.

The two issues that need to be addressed differently between adult and child learners are the use of prior knowledge and life experiences and learner responsibility. Both learners have prior knowledge and life experiences to bring to the learning situations. Adult learners make conscious decisions regarding the self-directed learning in which they participate. Child learners make unconscious decisions regarding the new knowledge that they internalize and make unconscious connections to their life experiences and prior knowledge. The adult learner consciously takes on responsibility for new learning for various conscious self-directed reasons. The child learner unconsciously takes responsibility for new learning based on unconscious understandings of the knowledge of a particular learning situation in which child is being immersed and receiving demonstrations by a significant other.

\section{REFERENCES}

Adult Education Centre (2005). Facilitation skills: Working with adult leaders. Dublin: University College.

http://www.ucd.ie/adulted/resources/pages/facil_adnrogog.htm

Alexander, P., \& Murphy, P. (1998). The research base for APA's learner centered psychological principles. In M. Lambert, \& B. Combs, (Eds.), How students learn: Reforming schools through learner cen- tered education. Washington DC: APA.

APA Work Group of the Board of Educational Affairs (1997). Learnercentered psychological principles: A framework for school reform and redesign. Washington DC: American Psychological Association.

APA Task Force on Psychology in Education (1993). Learner-centered psychological principles: Guidelines for school redesign and reform. Washington DC: American Psychological Association and Mid-Continent Regional Educational Laboratory.

Biancarose, G., \& Snow, C. (2004). Reading next: A vision for action and research in middle and high school literacy: A report to Carnegie Corporation of New York. Washington DC: Alliance for Excellent Education.

http://www.all4ed.org/publications/ReadingNext/index.html

Billington, D. (2007). Seven characteristics of adult education/adult learning.

http://meetingsnet.com/adult-learning/seven-characteristics-adult-edu cation

Boycoff B. J. (1998). Using learner centered assessment on a large scale. In N. Lambert, \& B. Combs (Eds.), How students learn: Reforming schools through learner centered education. Washington DC: APA.

Cambourne, B. (1988). The whole story: Natural learning and the acquisition of literacy in the classroom. Jefferson City, MO: Scholastic, Inc.

Glatthorn, A. A. (2000). The principal as curriculum leader: Shaping what is taught and tested (2nd ed.). Thousand Oaks, CA: Sage Publications.

Knowles, M. S. (1970). The modern practice of adult education: Androgogy versus pedagogy. New York: New York Association Press.

Knowles, M. (1975). Self-directed learning. Chicago, IL: Follet.

Knowles, M. (1984). The adult learner: A neglected species (3rd ed.). Houston: Gulf Publishing.

Knowles, M. (1984). Andragogy in action. San Francisco, SA: JosseyBass.

Knowles, M. S., Holton, E. F., \& Swanson, R. A. (2011). The adult learner: The definitive classic in adult education and human resource development (7th ed.). New York: Elsevier Inc.

Lieb, S. (1991). Principles of adult learning. Phoenix, AZ: VisionSouth Mountain Community College.

http://honolulu.hawaii.edu/intranet/committees/FacDevCom/guidebk /teachtip/adults-2.htm(\& 1.htm)

Mentkowski, M. (1998). Higher education assessment and national goals for education: Issues, assumptions, and principles. In N. Lambert, \& B. Combs, (Eds.), How students learn: Reforming schools through learner centered education. Washington DC: APA.

O’Brien, G. (2004). Principles of adult learning. Melbourne: Southern Health Organization.

http://www.southernhealth.org.au/cpme/articles/adult_learning.htm

Resnick, L. B. (1991). Shared cognition. In Resnick, Levine, \& Teasley (Eds), Perspectives on socially shared cognition. Washington DC: APA.

Richardson, V. (2005). The diverse learning needs of students. In D. M. Billings, \& J. A. Halstead (Eds.), Teaching in nursing (2nd ed.). St. Louis, MO: Elsevier.

Rogoff, B. (1990). Apprenticeship in thinking: cognitive development in social context. New York: Oxford University Press.

Smith, M. K. (2002) Malcolm Knowles, informal adult education, self-direction and andragogy. The Encyclopedia of Informal Education. http://www.infed.org/thinkers/et-knowl.htm

Tagliamont, S., \& Derek, D. (2006). LOI for real! Instant messaging, teen language and linguistic change. The Annual forum of the Linguistics Association of Canada and the United States (LACUS33), Toronto, ON.

Wiggins, G., \& McTighe, J. (2005). Understanding by design (2nd ed.). Alexandria, VA: ASCD.

Zemke, R., \& Zemke, S. (1995). Adult learning: What do we know for sure? http://www.msstate.edu/dept/ais/8523/Zemke1995.pdf 